\title{
À LA CARTE AND "FAMILY TIERS" AS A RESPONSE TO A MARKET DEFECT IN THE Multichannel Video Programming MARKET
}

\author{
T. Randolph Beard, ${ }^{\dagger}$ George S. Ford, ${ }^{\ddagger}$ and Thomas M. Koutsky ${ }^{*}$
}

\section{INTRODUCTION}

Many policymakers, both Republican and Democrat, have recently expressed concern over the content of video programming and, in particular, the practice of multichannel video programming distributors ("MVPDs") such as cable and satellite video providers to "bundle" a large number and variety of channels together into a "take-it-or-leave-it" package. It is common for MPVDs to make certain "must-have" programming (like CNN, ESPN, Nickelodeon, or The Discovery Channel) available only to those consumers in an "expanded basic" bundle that also includes other channels like MTV and SpikeTV that might contain content some subscribers may find objectionable.

Federal Communications Commission ("FCC" or "Commission") Chairman Kevin J. Martin has discussed this issue publicly and has repeatedly asked the MVPD industry to develop solutions that would give American households additional choice and control over the cable programming networks that they receive. ${ }^{\prime}$ On February 6, 2006, the FCC Media Bureau

\footnotetext{
$\dagger$ Ph.D., Economics, Vanderbilt University, 1998; Professor of Economics, Auburn University.

₹ Ph.D., Economics, Auburn University, 1994; Chief Economist, Phoenix Center for Advanced Legal \& Economic Public Policy Studies.

* J.D., University of Chicago Law School, 1991; Resident Scholar, Phoenix Center for Advanced Legal \& Economic Public Policy Studies. The views expressed in this paper are the authors' alone and do not represent the views of the Phoenix Center, its Adjunct Fellows, or any member of its Editorial Advisory Board.

1 S. Comm. on COMmerce, SCI., \& Transp., 109Th Cong., Open Forum on DeCenCy 9-12 (Comm. Print 2006) [hereinafter OPEN FORUM ON DECENCY] (statement of Kevin J.
} 
issued a report that found several potential benefits to "à la carte" (channelby-channel) provision of cable programming, from "combating rising MVPD rates and lowering consumer bills" and "offer[ing] consumers the ability to pay only for the programming that they value."2 The Media $\mathrm{Bu}$ reau report followed testimony by Chairman Martin before the Senate Commerce Committee in which he discussed his frustration with increasingly indecent programming and the unavailability of "family tiers" of programming that exclude potentially offensive material.

Members of Congress have also begun to take action. On June 7, 2006, Senator John McCain introduced the Consumers Having Options in Cable Entertainment ("CHOICE") Act. ${ }^{3}$ In introducing the legislation, Senator McCain said that despite calls for more programming package choices, cable companies "have continued to give consumers all the 'choice' of a North Korean election ballot." As discussed below, the CHOICE Act incorporates a carrot/stick approach to the issue, in an attempt to induce cable firms and programmers to offer channels on an à la carte basis to consumers. ${ }^{5}$ In 2005, Senator Ron Wyden took a different approach, proposing a bill that would require all cable providers offer a family-tier of at least fifteen channels. ${ }^{6}$

Many consumers and some commentators have supported these initiatives. ${ }^{7}$ But these initiatives have also come under attack, often on the ideo-

Martin, Chairman, Fed. Commc'ns Comm'n). Some cable and satellite MVPDs have begun to offer some form of family tier. Some of these, however, require consumers to subscribe to a basic tier of programming in order to benefit from a family package. Comcast, http://www.comcast.com/Localization/Localize.ashx?Referer=/shop/buyflow/default.ashx (enter "1600 Pennsylvania Avenue" and "20001" in the address and zip code boxes; select "Washington, DC" and follow "Thanks! On you go" hyperlink; follow "See All Features" hyperlink under "Family Tiers" heading) (demonstrating the White House could not subscribe to a Comcast Family Tier without also subscribing to a basic programming tier).

${ }^{2}$ In re À La Carte and Themed Programming and Pricing Options for Programming Distribution on Cable Television and Direct Broadcast Satellite Systems, Further Report on the Packaging and Sale of Video Programming Services to the Public, MB Docket No. 04207, II 111 (Feb. 9, 2006) [hereinafter $2006 \dot{A}$ La Carte Report]. À la carte programming allows consumers to subscribe to individual channels of their choosing.

3 Consumers Having Options in Cable Entertainment Act, S. 3457, 109th Cong. (2006); see also John McCain \& Kevin J. Martin, John McCain: Make Cable Go À La Carte, L.A. TIMES, May 25, 2006, at B11.

4152 CONG. REC. S5600 (daily ed. June 7, 2006) (statement of Sen. John McCain).

5 See generally Consumers Having Options in Cable Entertainment Act, S. 3457, 109th Cong. (2006)

6 Kid Friendly TV Programming Act of 2005, S. 946, 109th Cong. § 3 (2005).

7 See, e.g., Cesar. V. Conda, Cable, à La Carte?, NAT'L Rev. ONLINE, Jan. 12, 2006, http://www.nationalreview.com (select "Search" tab; select "National Review Online" hyperlink; enter "cable, a la carte" in the keyword box; select "NRO articles" in the "Sections" drop-down menu; select "Search" and then select "Cable, a la Carte?" hyperlink to view article by Cesar v. Conda) ("Conservatives of all stripes should commend FCC chairman Martin for using the enlightening power of the Bully Pulpit"); Press Release, Con- 
logical ground that a government requirement that an MVPD offer a "family tier" or "à la carte" programming is an unwise and dangerous interference with free market principles. ${ }^{8}$ The general thread of these criticisms is that cable companies are simply offering consumers the services that they want, so if consumers continue to purchase these bundles of programming, it is not the government's role to intervene in those decisions. ${ }^{9}$ One commentator has even argued that in a competitive market, "self-interest (the need to retain customers) will compel competitive firms to select the pricing strategy that their customers prefer."10

This article describes a set of circumstances in which a market defect will lead to the bundling of objectionable with desirable content-even in competitive video distribution markets. ${ }^{11}$ This approach is practical and not philosophical. The purpose is to present an economic model illustrating the circumstances or conditions in which a multichannel video programming provider might decide that it is more profitable to deliver particular channels of video programming to households in a "forced bundle" that does not give consumers the option to exclude objectionable programming from the bundle. The analysis uncovers one set of conditions that makes these "forced bundles" resistant to changes in market structure, in that forced bundles appear in both monopolist and competitive structures. It finds that the practice of forced bundling may persist even in fully competitive video markets. The analysis shows that simplistic arguments that cable companies are simply using "the pricing strategy that their customers" prefer is fundamentally flawed. These findings instead suggest that investigations by both academics and government into the causes and consequences of "forced bundling" may be legitimate, since this model shows that con-

cerned Women for America, CWA Endorses McCain's Cable Choice Bill (June 7, 2006), available at http://www.cwfa.org/articledisplay.asp?id=10908\&department=MEDIA\& categoryid=misc.

${ }_{8}$ See, e.g., Adam Thierer, Moral and Philosophical Aspects of the Debate over A La Carte Regulation (The Progress and Freedom Foundation, Progress Snapshot, Release 1.23, Dec. 2005), available at http://www.pff.org/issues-pubs/ps/ps1.23alacarte.pdf (last visited Nov. 12, 2006) ("[Y]ou have no 'right' call [sic] upon government to upend an industry's private business arrangements"). Thierer also called Sen. Wyden's bill "government nannyism for cable TV." Adam Thierer, "Kid-Friendly" Tiering Mandates: More Government Nannyism for Cable TV (The Progress and Freedom Foundation, Progress Snapshot, Release 1.2, May 2005), available at http://www.pff.org/issues-pubs/ps/ps1.2familyfriendly tiering.pdf.

9 See infra Part IV.A-E and accompanying footnotes.

10 Steven S. Wildman, A Case for A La Carte and "Increased Choice"? An Economic Assessment of the FCC's Further Report 20 (Mar. 9, 2006) (unpublished manuscript), available at http://www.ncta.com/DocumentBinary.asp?id=203 at 20 (scroll to bottom of web page and select the hyperlink "Wildam Paper 031506.pdf") (last visited Nov. 12, 2006).

11 "Objectionable" content refers to content from which the consumer derives a negative utility. 
sumer welfare is unambiguously improved with the elimination of forced bundles.

Section II presents a brief background on the issue of à la carte and forced bundling in the purchase of video programming. Section III contains a simple economic model in which a third party (e.g., advertisers and programmers) compensates the cable provider for bundling certain undesirable channels with desirable ones. The presence of this third party does not, in and of itself, create a "market failure," but it does interfere with the ability of consumers to communicate their bundling preferences to MVPDs and have those preferences fully realized. Rather than a "market failure," this effect could more appropriately be called a "market defect"-but whatever one calls it, it is certainly a failure from the consumer's point of view. ${ }^{12}$ The influence of the third party is not alleviated by changes in market structure, as forced bundling is shown to be resistant to competitive entry. Since the transaction costs of organizing a coalition of consumers to pay for the exclusion of objectionable content are likely to be prohibitively high, an argument for the government to act as an agent is not unreasonable. Section IV outlines some potential policy responses, recognizing that any effort to resolve this problem with government intervention requires the policymaker to invest in fully understanding the sources and nature of bundling, so that any rules can be precisely targeted.

\section{BACKGROUND}

Most consumers who purchase cable services purchase an "expanded basic" tier of channels, ${ }^{13}$ which is usually priced at a fixed monthly cost. ${ }^{14}$ Many of the most popular cable programming services are found on this expanded basic tier-programs as diverse as "The Iron Chef,"15 "MythBusters,"16 and "Poirot." ${ }^{\prime \prime}$ But the expanded basic tier also contains

12 The complete social welfare consequences of these practices are beyond the scope of our analysis. See generally Avinash Dixit \& Victor Norman, Advertising and Welfare, 9 BELL J. ECON. 1 (1978) (examining the relationship of private profitability and consumer tastes in several market settings).

13 See Leslie Cauley, How We Pay for Cable May Be About to Change, USA TODAY, Mar. 1, 2006, http://www.usatoday.com/tech/news/2006-03-01-ala-carte-cable_x.htm (discussing tradition cable packages and payment schemes); Family Choice Act of 2006, H.R. 5919 , 109th Cong. $\$ 2$ (1) (2006) ("88 percent [of cable consumers] subscribe to [an] expanded basic service.").

14 See id.

15 "The Iron Chef" is a Food Network program in which several chefs compete in a cooking competition against the reigning champion. See Iron Chef, http://www.foodnetwork.com/food/show_ic (last visited Nov. 12, 2006).

${ }_{16}$ "Mythbusters" is a Discovery Channel program where special effects experts test the veracity of myths by reconstructing them in controlled experiments. See Discovery Channel, Mythbusters Fan Site, http://dsc.discovery.com/fansites/mythbusters /mythbusters.html (last visited Nov. 12, 2006). 
programming that some families-particularly parents of school-aged children-might prefer not to have available.

For example, a recent show on MTV entitled "I'm on Steroids" documented one man's attempt to get on the cover of a fitness magazine by taking steroids "under the supervision of professionals." 18 Another MTV show, called "Homewrecker," showed how to "Make Your Very Own Torture Room." SpikeTV sported an animated show called "Stripperella," which starred Pamela Anderson as the voice of Erotica Jones, "a stripper by night and superhero Stripperella by even later at night." 20

While no one forces consumers to watch programming they do not prefer, many have argued that the ready and easy availability of this type of programming to children creates important social problems and costs. Despite these opportunities, the fact remains that a family that wishes to have access to CNN, ESPN, or The Discovery Channel, in the overwhelming majority of cases, must also accept access to MTV and SpikeTV as part of the bundle.

In addition to this impact on families, bundling of video programming presents other complicated issues. FCC economists Keith Brown and Peter J. Alexander have presented a conceptual analysis of programming network bundling, and they found that bundling can be a method in which a firm with market power can capture monopoly rents from consumers, but that certain types of bundling also can be an efficient response by the MVPD to competition. ${ }^{21}$ Brown and Alexander also note that "bundling may be used as a tool that incumbents use to foreclose entry."22

17 "Poirot" is a British television series documenting the investigations of Agatha Christie's fictional detective Hercule Poirot. See Poirot Television Show, TV.com, http:/www.tv.com/poirot/show/3573/summary.html (last visited Nov. 12, 2006). The program is broadcast internationally and has appeared in the United States on the Arts \& Entertainment Network (A\&E). Id.

18 MTV.com, True Life: I'm on Steroids, http://www.mtv.com/ontv/dyn/truelife/ episodes,jhtml (select "Epsiode Guide" hyperlink and then select "Episode 27") (last visited Nov. 12, 2006). The True Life program series presents short documentaries about the lives of young adults, ranging from following a person through a diet to documenting a soldier's return from Iraq. $I d$.

19 MTV.com, Homewrecker, http://www.mtv.com/ontv/dyn/truelife/series.jhtml\#/ontv/ dyn/homewrecker/series.jhtml (last visited Nov. 12, 2006). In each episode, the host of the series helps one roommate creatively "trash" his or her cohabitant's personal space. Id. (follow "Read More" hyperlink).

20 See SpikeTV.com, Stripperella, http://www.spiketv.com/\#/shows/index.jhtml (select "Shows" hyperlink; select "Vintage" hyperlink; and follow "Striperella" hyperlink) (last visited Nov. 12, 2006); Internet Movie Database, Stripperella, http://www.imdb.com/title/tt0369171/ (last visited Sept. 21, 2006).

${ }_{21}$ Keith Brown \& Peter J. Alexander, Bundling in Cable Television: A Pedagogical Note With a Policy Option, 6 INT'L J. Media MgMT. 162, 162 (2004).

22 Id. at 165. 
Defenders of the industry's "forced bundling" of program networks admit that there is a form of cross-subsidy involved in this practice. ${ }^{23}$ A 2004 FCC Media Bureau report largely supported the cable industry's position and stated that bundling of channels requires consumers to "crosssubsidize each others' viewing habits, allowing new and diverse programming to survive in the marketplace." 24 Critics of forced bundling decry these cross-subsidies, but there is at least some consensus on the point that cross-subsidization motivates the practice of bundling video programming networks.

Perhaps the most perplexing thing about à la carte programming is that so little of it exists. Brown and Alexander note that a policy of mixing bundles and à la carte pricing could "allow[] the monopolist to price the bundle very high, to capture the consumers with a high total valuation of all the channels, and still capture some consumers with a very high valuation of particular channels." ${ }^{25}$ A multi-tier strategy is essentially a form of price discrimination, ${ }^{26}$ so it would seem logical that a menu of programming options that involve multiple combinations of a "family tier," along with an "adult contemporary tier" or "scatological content tier," would, if properly implemented, generate higher profits for a firm. Yet this does not happen except in certain circumstances (notably, sports, movies, and Playboy/Spice, none of which contain channels generally available on the expanded basic tier level).

With digital cable services, there does not seem to be a significant technological reason as to why making a multitude of à la carte and tiers is not possible. Digital capability offers the ability to offer more à la carte programming, through pay-per-view or video-on-demand services, more costeffectively than it might have been before. ${ }^{27}$ In the days of analog cable service (which have yet to pass completely), high equipment or software costs to exclude particular channels from the bundle might have justified the sale of programming in large bundles. Analog cable systems often used filters and traps to block certain channels, but it was notoriously easy for consumers to circumvent those devices. But, even in the days of analog

23 See Thomas Hazlett, et al., Debate: Cable TV Rates: Has Deregulation Failed?, Manhattan Institute for Policy Research, Center for the Digital Economy (Nov. 21, 2003) (transcript available at http://www.manhattan-institute.org/html/cde11-21-03.htm).

24 In re À La Carte and Themed Programming and Pricing Options for Programming Distribution on Cable Television and Direct Broadcast Satellite Systems, Report on the Packaging and Sale of Video Programming Services to the Public, MB Docket No. 04-207, at 5 (Nov. 18, 2004) [hereinafter 2004 À La Carte Report]. However, the Media Bureau's 2006 report on the topic noted that "the cross-subsidization that the [2004] Report portrays as a valuable feature of bundling can actually be harmful to consumers and society." $2006 \AA$ La Carte Report, supra note 2, II 38 (citations omitted).

25 Brown \& Alexander, supra note 21, at 165.

26 Id. at 162.

27 Burt Helm, Cable a la Carte: Choice v. Cost?, Bus. WK., Dec. 7, 2005, http://www.businessweek.com/technology/content/dec2005/tc20051207_647629.htm. 
cable, some programming was still sold on an à la carte basis, such as HBO. In a digital cable environment, however, the argument that it is difficult as a hardware, software, or enforcement matter to offer channels solely on an à la carte basis is weak. The 2006 FCC Media Bureau Report notes "a substantial share" of the costs of deploying a la carte is accounted for by digital transmission, a conversion that "is occurring independently of any à la carte options." 28 The technology for complete à la carte for digital cable subscribers is now clearly possible. ${ }^{29}$ Given the potential profit opportunities that might await cable operators from selling programming à la carte, the fact that video services are not generally sold in this way today must have a different explanation.

The following section outlines an economic model to help explain why a cable firm would create bundles combining undesirable with desirable programming. This model shows that the presence of advertising revenues or some other off-setting factor, like programming distribution transaction costs, plays a significant role in setting the size of the expanded basic tier. Stated another way, MVPDs do not create their tiers of programming solely by reference to what consumers want to watch (or not watch)-an MVPD establishes tiers in order to maximize profits. Those profits include advertising revenues and programming licensing considerations, which, in essence, require that popular programming networks be bundled with new and niche channels. ${ }^{30}$ As a witness for the Dish Network, one of the nation's largest MVPDs, David J. Moskowitz testified before the Senate Committee on Commerce, Science and Transportation:

We've also considered offering a family tier, but are currently prevented from doing so by our existing contracts with programmers. . . . [L]arge content providers require the bundling of multiple core popular programming networks, only some of which would be considered family friendly. Again, in these circumstances, the programming vendors will not sell the family friendly channel or will only offer it at an uneconomic price, unless we agree to accept several of the vendors' other channels and place these other networks in the same programming tier. ${ }^{31}$

282006 À La Carte Report, supra note 2, III 60-61. The National Cable and Telecommunications Association reports that there are 32.9 million digital cable subscribers as of June 2006, roughly half of the 65.5 million cable households in the country. Nat'l Cable \& Telecomm. Ass'n, Statistics, NCTA.com, http://www.ncta.com/ContentView.aspx ?contentId=54 (last visited Nov. 13, 2006).

${ }^{29}$ See Eric Hellweg, Watching Channel Zero, TECH. REv., Aug. 5, 2004, http://www.technologyreview.com/read_article.aspx?id=13719.

30 See infra note 34 and accompanying text.

31 OPEN FORUM ON DECENCY, supra note 1, at 34-35 (statement of David J. Moskowitz, Executive Vice President/General Counsel, EchoStar). Senator McCain has discussed the efforts of a cable system in Sun City, Arizona to drop expensive music channels like MTV from the subscriptions of its senior citizens subscribers, "but the owners of the music video channels have forbid [cable systems] to do so without serious repercussions. So the residents of Sun City continue to subsidize the cost of these channels for viewers around the country." 152 CONG. REC. S5600 (daily ed. June 7, 2006) (statement of Senator John McCain). 
The intervention of third parties with market power in the exchange between the MVPD and the consumer can create a type of market defect that results in consumers purchasing programming that they would prefer not to receive. The "market defect" is that the forced purchase of undesirable programming will occur in both monopolistic and competitive settings in the retail distribution market, and that consumers are unable to influence bundling decisions (in either of these competitive extremes). Thus, even if a market performs well by traditional measures, consumer surplus might be reduced by the "forced bundling" of offensive programming with desirable programming.

\section{MODEL}

This economic model tries to explain the reasons why a MVPD would choose to sell programming to consumers only in "bundles" that contain programming that the consumer may not wish to purchase. The model shows that the presence of a third party, such as an advertiser or a video programming vendor (like Disney or Viacom), will result in programming carriage and bundling decisions that will be sub-optimal to particular consumers. Moreover, the analysis finds that this sub-optimal outcome occurs both in monopoly and competitive/contestable market conditions. As a result, one cannot simply posit that a "competitive" MVPD market will alleviate this problem.

To make this model simple, it assumes only two consumers (1 and 2) and two channels (A and $\mathrm{B}$ ). Consumers value these products at $V i j$ (the value of channel $j$ to customer $i$ ). The value $V i j$ can be negative-this means that the consumer does not like the channel and would consider himself to be better off if the channel were not piped into his home. The costs of delivering a channel to a household are given by the cost function $C(a, b)$ where $a$ and $b$ count the number of subscribers who get each channel. For example, $C(2,1)$ implies the seller sells 2 units of channel $A$ and 1 unit of channel B. Table 1 summarizes potential combinations of output and illustrative values of cost. Both scale and scope economies are present.

\section{Table 1: Potential Costs with Illustrative Values}

\begin{tabular}{|l|l|}
\hline$C(1,0)=5$ & $C(1,2)=10$ \\
\hline$C(0,1)=6$ & $C(2,0)=8$ \\
\hline$C(1,1)=8$ & $C(0,2)=9$ \\
\hline$C(2,1)=9$ & $C(2,2)=11$ \\
\hline
\end{tabular}

The following conditions have been imposed on the models. First, the values from the channels are additive, so that $V A+V B=V A B$ (ignoring the consumer subscript). In other words, the values of the channels are inde- 
pendent. Second, costs do not vary depending on the identity of the customer.

\section{A. Example 1: When À La Carte Should Happen}

It is easy to construct an example in which the cable firm would offer channels on an $a$ la carte basis to the two customers. If customer values Network $A$ at $10(V A=10)$ and values Network $B$ at $-1(V B=-1)$, then the value of a bundle of Networks $A$ and $B$ to the consumer is $9(V A B=9)$. Using the costs from Table 1, the cable company would generate a profit of only 1 by selling a bundle of $\mathrm{A}$ and $\mathrm{B}$ to the consumer $(C(1,1)=8)$. An à la carte offering, however, actually increases the value of the cable firm's goods to this consumer (to 10) and reduces cable firm's cost to 5 $[C(1,0)=5]$. Thus, in this situation, à la carte pricing is more profitable than a forced bundle.

Importantly, the cost figures in Table 1 include a "discount" to the seller for offering both channels $(8<5+6)$. Thus, even if each channel is more costly if purchased alone (or, there is some cost to exclude a channel), à la carte pricing is profitable. This is always true when the value of a channel is negative and the cost of the channel is positive. ${ }^{32}$

Example 1 shows two simple but important conditions that are critical for à la carte pricing to happen: the potential value from à la carte availability to the consumer must be higher than the value of a larger bundled product, or the cable firm's costs must be lower if its services were sold on an à la carte basis. These two factors are independent of one another. If a consumer truly despised Network $B$ so that $V B=-11$, then the cable firm's costs need not change at all for it to recognize the value of à la carte pricing. In this case, if an $\mathrm{A} / \mathrm{B}$ bundle is created, then the consumer does not purchase the product because he assigns a negative value to the bundle. Even if the cable operator's costs from providing à la carte services for Network A (say, $\mathrm{C}(1,0)=9$ ) is higher than the cost of providing the $\mathrm{A} / \mathrm{B}$ bundle $(\mathrm{C}(1,1))$, then it might still find it profitable to make this option available to this consumer.

\section{B. The Presence of a Third Party}

Video services are not bought and sold as described in Example 1. Importantly, third parties (notably, advertisers and programmers) are part of the MVPD industry's profit calculations and cannot be ignored. Indeed, as noted above, one of the nation's largest MVPDs, the Dish Network, has publicly stated that the practices of programmers and advertisers may be most responsible for the failure of consumers to obtain à la carte program-

32 If the value exceeds the cost, then bundling is profitable. 
ming. ${ }^{33}$ The presence of a third party is important because it affects the revenues and profits of a cable firm that offers a menu of products. ${ }^{34} \mathrm{~A}$ third-party advertiser pays the cable or satellite firm according to viewers and/or subscribers, while a third-party programmer charges the cable or satellite firm according to subscribers.

For the following examples, let us assume that this third party (say, an advertiser) pays the multichannel video provider some amount $S A \geq 0$ for each subscriber that receives Network $A$, and $S B \geq 0$ for each subscriber that receives Network B. ${ }^{35}$ This payment-per-eyeball approach is generally consistent with the nature of transactions in the advertising industry. ${ }^{36}$ While this focus is on the role of the advertiser in these examples, the same could be said for programming vendors that wish to sell a portfolio of cable programming networks to an MVPD. Several MVPDs have alleged that programming vendors "tie" the sales of all of their networks together that require that all networks be purchased and placed on the same tier, or that these vendors offer channels on an à la carte basis but only at higher prices. ${ }^{37}$ In this sense, an MVPD that wishes to offer multiple tiers or à la carte channels will face higher costs. ${ }^{38}$ That situation leads to similar decisions as to a situation in which an MVPD would receive lower advertising revenues if it offered more tiers or à la carte programming.

\section{Example 2: Forced Purchase of Undesirable Channels Under Monopoly}

Example 1 describes the situation in which the MPVD, in the absence of a third party, would be better off with à la carte pricing. In Example 1, bundling reduces the maximum price the seller can charge for a bundle and eliminating the channel reduces costs. As a result, the MVPD will not require the consumer to purchase Networks $A$ and $B$ in a bundle.

Now enters a third party that is willing to pay the MVPD if the consumer receives Network $B$ (the network the consumer does not like) or the third party will increase the costs of the MVPD for carrying Network $A$ if it does not distribute Network B on the same tier. As a result, the consumer's willingness to pay $(V)$ is not the only revenue issue for the MVPD. Whether or not to force the bundle on the consumer or offer à la carte pric-

\footnotetext{
33 See supra note 31 and accompanying text.

34 An advertiser pays a cable or satellite MVPD according to numbers of viewers and/or subscribers. Likewise, a programmer charges a cable or satellite MVPD for the programming according to the number of subscribers. This is known as the "payment-per-eyeball" approach. See generally Jim Surmanek, Media Planning: A PRaCtical Guide (3rd ed. 1996).

35 The value of the advertisements, $S$, is a function of the viewership of the channel.

36 See generally SURMANEK, supra note 34.

37 See infra note 42 and accompanying text.

38 See id.
} 
ing depends on which option offers the greatest profits. These profits are affected by a third party.

The relevant condition for forced bundling can be derived as follows. Say Consumer 1 likes Network $A(V A l>0)$ and Network B $(V B I>0)$, but Consumer 2 dislikes Network $\mathrm{B}(V B 1>0, V B 2<0)$. If so, the cable company has two relevant options: (1) it can force a bundle on both consumers or (2) it can offer only a bundle to Consumer 1 and à la carte pricing to Consumer 2 (a "mixed bundle"). 39

Which strategy is more profitable? To see, let:

$P_{\mathrm{AB}}{ }^{\prime}=$ bundle price in a forced bundle;

$P_{\mathrm{AB}}{ }^{*}=$ bundle price in a mixed bundle; and

$P A^{*}=$ channel A price in mixed bundle.

The profit of the seller with a forced bundle is:

$$
\pi_{F}=2 P_{A B}{ }^{\prime}-C(2,2)+2 S_{A}+2 S_{B},
$$

and with the mixed bundle is:

$$
\pi_{M}=P_{A B}^{*}+P_{A} *-C(2,1)+2 S_{A}+S_{B} .
$$

The difference in the profits is:

$$
\pi_{F}-\pi_{M}=\left(2 P_{A B}{ }^{\prime}-P_{A B}^{*}-P_{A}^{*}\right)-[C(2,2)-C(2,1)]+S_{B} .
$$

To clean up a little, let $C(2,2)-C(2,1)=I C_{b}$, which is the incremental cost of one more channel $B$. The monopolist forces the bundle on both Consumers 1 and 2 if:

$$
\left(2 P_{A B}{ }^{\prime}-P_{A B}^{*}-P_{A}^{*}\right)-I C_{b}+S_{B}>0 .
$$

Since Consumer 2 has a negative value for channel $B$, presumably we have $\left(2 P_{A B}{ }^{\prime}-P_{A B}^{*}-P_{A}^{*}\right) \leq 0$. If we accept this to be true, then $\left(2 P_{A B}{ }^{\prime}-P_{A B}{ }^{*}-P_{A}^{*}\right)=0$ is as large as this expression can be. So, a necessary condition for forced bundling is $S B>I C b$; that is, the extra dollars from the third-party source (advertising) exceeds the incremental cost of providing the channel to Consumer 2 . The larger the distaste of channel $B$ by Consumer 2, the larger $S B$ must be to force the bundle. But if $S B$ is

39 William J. Adams and Janet L. Yellen, Commodity Bundling and the Burden of Monopoly, 90 Q. J. ECON. 475 (1976). These are "relevant" options in that other options are less profitable. 
large enough, the bundle will be required even if Consumer 2 has a strong distaste for Network B.

Example 2 reveals an important concept: if an MVPD receives revenues $(S B)$ from another source, like an advertiser, it may bundle programming to consumers that the consumer would prefer not to view. In this sense, bundling of channels on an "expanded basic" tier is similar to unsightly billboard advertising-drivers and neighbors may dislike a billboard intensely but may not necessarily have a "say" as to the content or presence of the billboard, which is worked out between the property owner and the firm paying for the ad. Proponents of forced bundles admit that this practice occurs-they extol this "cross-subsidization" in which consumers pay for and receive programming they do not want as part of a bundle in order that other consumers can see that programming. ${ }^{40}$

It is important to understand that $S B$ need not be additional revenue to a cable operator-it could represent lower costs (perhaps usefully thought of as a rebate on the price of programming). Consider the situation in which a cable operator is negotiating with a large programmer that produces a number of cable programming networks (like ABC/Disney or Time Warner). The programmer may offer all of its networks in a "take it or leave it" package that requires that all affiliated programming networks be packaged as part of the expanded basic tier. A programmer also may structure the pricing of its channels so that placing only a few networks in the expanded basic tier but not the others would be prohibitively expensive for the cable operator. Packages including "must have" channels like network broadcast affiliates and ESPN exacerbate this practice. It has been alleged that the current broadcast-cable retransmission consent rules encourage and facilitate these arrangements, which has led to the proliferation of networks affiliated with the major broadcast networks like $A B C$ Family and MSNBC. ${ }^{41}$ In these examples, $S B$ would represent the avoided additional cost that a cable operator would incur if it did not place Network B in the expanded basic tier. If that cost includes the inability to carry a local broadcast affiliate of $\mathrm{ABC}$ or $\mathrm{NBC}$, then $S B$ would be relatively high and lead to a number of cases of forced bundling.

D. Example 3: Forced Purchase of Undesirable Channels Under Competition

It might be simple to assert that increasing the number of MVPDs would result in programming tiers more tailored to individual consumer tastesand that if such tailoring of preferences does not occur and large "ex-

\footnotetext{
40 See supra notes 31-33 and accompanying text.

41 See 47 U.S.C. $\$ 325$ (b) (2000) (prohibiting the retransmission of a signal without the consent of the originating station); 47 C.F.R. $\$ 76.64$ (2005).
} 
panded basic" bundles proliferate in a competitive environment, then government should not worry about that result. But that argument fails to consider that some market defects persist even in competitive markets. A closer examination shows that the presence of third-party advertisers and programmers directly interfere with the MVPD-subscriber relationship, and this interference is independent of market structure.

With large scale and scope economies, which have been assumed, competition is costly and, therefore, less likely. Nevertheless, this model can evaluate the effects of competition on bundling by using contestable market theory. ${ }^{42}$ In essence, contestable market theory suggests markets render results consistent with competition even if a monopolist serves the market. Or, contestable market theory assumes that because of the threat of competitive entry, firms will price so that they reap zero monopoly profit.

With zero profits, a firm selling a bundle in a contestable market would price the bundle accordingly:

$$
2 P_{A B}^{\prime \prime}-C(2,2)+2 S_{A}+2 S_{B}=0
$$

so:

$$
2\left(P_{A B}^{\prime \prime}+S_{A}+S_{B}\right)=C(2,2) .^{43}
$$

Now let us consider the question of a firm that seeks to enter the market and it is considering various pricing schemes, including à la carte. If the entrant sells Customer 1 a bundle of Networks A and B, then its profits are:

$$
P_{A B}+S_{A}+S_{B}-C(1,1)<0
$$

The firm will not make money if the entrant tries to sell Customer 1 the bundle of Network $A$ and $B$.

If the entrant tries to serve Customer 1 the bundle of Networks A and B, its profits will be:

$$
P_{A B}^{*}+P_{A}+2 S_{A}+S_{B}-C(2,1)<0
$$

Unfortunately for the entrant, this strategy is unprofitable as well. Example 2 shows that the incumbent will force a bundle of Networks A and B if:

$$
2 P_{A B}^{\prime \prime}-C(2,2)+2 S_{A}+2 S_{B} \geq P_{A B}^{*}+P_{A}^{*}-C(2,1)+2 S_{A}+2 S_{B}
$$

42 See generally William J. BAUMOL, ET AL., CONTESTABle MARKETS AND THE THEORY OF INDUSTRY STRUCTURE (1982), for an explanation of contestable markets theory.

43 Without price discrimination, $\mathrm{C}(2,2) / 2$ is equal to average incremental cost. 
Yet we know that the left-hand side of Eq. (9) is zero by Eq. (5)-that is, the incumbent has set its prices so that it is earning no super-competitive profits. As a result, Eq. (8) must be negative, so entry is unprofitable.

So, in a contestable market setting, an incumbent will be able to maintain a forced bundle against a competitive entrant. Competition at the local MVPD distribution level alone, under certain conditions, may not protect consumers from bundles of undesirable and desirable programming.

\section{E. Impact of Bundling on Welfare}

Under some conditions, an MVPD might require a consumer to purchase programming networks he or she does not desire in order to obtain access to programming networks he or she wants. This practice of "forced bundling" in the expanded basic tier can occur if blocking that channel increases the MVPD's costs or if the presence of a third party (such as an advertiser or programmer) increases the revenues of a MVPD for these forced bundles.

The social welfare effects in the video programming industry are difficult to determine for a number of reasons. First, the market that produces the prices $S$ has not been formally modeled in this article. As part of this analysis, one must consider that the benefits to the advertiser of the customer contact (equal to at least $S$ ) and any effects on consumer welfare from the purchase of advertised products. ${ }^{44}$ Also, there may be direct costs experienced by the seller caused by providing the advertisement, and these costs offset the benefits to the advertiser in a welfare calculation.

What is clear, however, is that consumer welfare unambiguously rises if the consumer can avoid purchasing undesirable channels as part of a bundle. The interest of Chairman Martin and other policymakers regarding family tiers and à la carte solutions could be seen simply as evidence that the interests and welfare of consumers are being articulated by policymakers.

\section{F. Practical Issues}

This theoretical framework has revealed that forced consumption of undesirable channels may be resistant to competition. Thus, even a well functioning market may fail to satisfy reasonable consumer demands (i.e., not buying programming they find offensive), because third-party advertisers and programming vendors affect the carriage and tiering choices that

\footnotetext{
44 The value, positive or negative, of the actual advertisement (not the product advertised and potentially purchased) is included in $V$. In other words, if advertising has negative value, then $V$ will lessen the more that advertising content appears on the channel.
} 
MVPDs make, and transactions costs effectively prevent consumers from participating in these decision.

This result is much like findings of economic theory that the relative quality of services provided between monopoly and competition is ambiguous. ${ }^{45}$ In essence, a monopolist has an incentive to increase demand through quality improvements as do firms with rivals, and in some cases the incentive for quality is greater for monopoly. It is also similar to the inability of economic theory to provide compelling theoretical evidence that competitive firms are more efficient than monopoly firms. ${ }^{46}$

In practice, however, we often observe that competition lowers prices, raises quality, and increases firm efficiency. ${ }^{47}$ The failure of theory to produce these results in an unambiguous fashion is a shortcoming of theory, not of experience. So, while it is quite possible that competition may help resolve or mitigate instances of "forced bundling," the risk (and reasons) that it might not should be thoroughly investigated.

\section{POLICY APPROACHES}

The preceding analysis shows that policymakers cannot simply make face-value assertions that consumers "always have the option of declining" to purchase cable programming ${ }^{48}$ or that if the market is sufficiently competitive, MVPDs will offer consumers bundles and tiers "in the form they want them." ${ }^{, 49}$ Instead, the analysis shows (a) that there is the potential for a market defect that may result in the distribution of programming to consumers that consumers would not otherwise choose to purchase except for forced bundling and (b) that consumers are effectively unable to do anything about it.

In particular, this model shows that in certain circumstances, a variety of factors may work in a manner that makes desirable video programming (like CNN and ESPN) available only through an "expanded basic" tier that

45 See generally Michael Mussa \& Sherwin Rosen, Monopoly and Product Quality, 18 J. ECon. Theory 301 (1978); David de Meza, Product Diversity Under Monopoly: Two High Quality Results, 49:2 BuLL. ECON. RES. 169 (1997); LAWRENCE ABBoTT, QuALTYY AND COMPETITION: AN ESSAY IN ECONOMIC THEORY (1995).

46 Hal R. Varian, Entry and Cost Reduction, Feb. 18, 1994 (unpublished manuscript, available at http://www.sims.berkeley.edu/ hal/Papers/entry.pdf).

47 U.S. Gen. ACCOUNTING OFFICE, TelecommuniCATIONS: WiRE-Based CoMPETITION BENEFITED CONSUMERS IN SElECTED MARKETS 4 (2004). See also T. Randolph Beard, et al., Fragmented Duopoly: A Conceptual and Empirical Investigation, 78 J. Bus. 2377 (2005) for a discussion of the effects of wireline distribution network competition on cable television market prices, demand, and quality.

482004 A La Carte Report, supra note 24, at 85.

49 In re A La Carte and Themed Tier Programming and Pricing Options for Programming Distribution on Cable Television and Direct Broadcast Satellite Systems, Comments of the Progress and Freedom Foundation, MB Docket No. 04-207, at 2 (July 15, 2004) (accessible via FCC Electronic Comment Filing System). 
also contains cable programming networks that a number of consumers prefer not to receive, let alone pay for. This circumstance can be the result of a number of conditions, such as an inability of consumers to contract with upstream content providers or other third-party interventions. It can also be caused by public policies that reinforce the ability of a video programming vendor to require that all of its affiliated video networks be placed on the same tier, without regard to whether certain of those networks may or may not be family friendly.

Because forced bundling can be the result of market defects or of public policy, it is legitimate for concerned policymakers to examine potential public policy responses. However, any public policy response should be targeted at the root causes or conditions that might lead to inordinate forced bundling. To the extent that policymakers believe intervention is required, a number of potential strategies can be utilized that are directed at the real source of forced bundling. This section discusses potential approaches for policymakers, some of which have been proposed, others not, and assesses whether those approaches address the root causes or conditions of forced bundling. It should be noted that addressing the root causes may involve strategies that do not simply mandate "family tiers" and à la carte programming. Other alternatives may exist, though they are merely thoughts at this point, and we have not conducted any meaningful cost/benefit analysis of any the proposals. Nevertheless, we believe it is worthwhile to initiate the discussion of some potential solutions.

\section{A. Subscriber-Selected Tiers}

FCC economists Keith Brown and Peter J. Alexander note that the practice of bundling channels holds the promise of being efficiency-enhancing yet also harmful to consumers. ${ }^{50}$ To resolve this ambiguity, Brown and Alexander outline one potential solution that might advance consumer welfare:

Allow the cable operators to sell bundled packages of channel space to consumers at a given price, and then allow consumers to choose which channels they put on that space. For example, cable operators could sell a package of 25 channels for $\$ 30$ and for package of 50 channels for $\$ 55$, but consumers would then choose what those 25 or 50 channels would be. ${ }^{51}$

The 2006 FCC Media Bureau report called this proposal "subscriberselected tiers" and noted that two Canadian cable operators, Videotron and Rogers Cable, already offer this type of pricing to consumers. ${ }^{52}$

Implementing this approach would, of course, involve some complexity as cable programming networks charge different prices to MVPDs for dis-

\footnotetext{
50 Brown \& Alexander, supra note 21, at 165.

51 Id.

522006 À La Carte Report, supra note 2, TII 99-101.
} 
tribution. Implementation might require the renegotiation of programming delivery contracts; but then again, that would be the point. As a result, third parties like advertisers and programming vendors would not be able to insist that particular networks be sold on particular tiers, at least not exclusively. ${ }^{53}$

The attractiveness of this approach lies in the fact that it would permit an MVPD to recover fixed costs, but in a way in which consumers select (and pay for) the channels most valuable to them. Indeed, the pricing strategy would permit the MVPD to engage in efficiency-enhancing price discrimination in a more targeted way than one-size-fits-all "expanded basic" bundles. ${ }^{54}$ As Brown and Alexander note, consumers "would self-select in such a way so that the final equilibrium would be identical to the price discrimination bundling equilibrium." 55

At the same time, Brown and Alexander note that this option might reduce consumer welfare and total economic welfare if the MVPD had sufficient market power. ${ }^{56}$ As a result, this option might best be undertaken in conjunction with other steps to promote competition and entry into the industry, such as cable franchise reform.

\section{B. Regulatory Mandate: The Kid-Friendly TV Programming Act}

In 2005, Senator Ron Wyden introduced S. 946, the Kid-Friendly TV Programming Act. ${ }^{57}$ Senator Wyden's approach would require all MVPDs to offer a family-friendly tier that includes at least fifteen channels, with a risk of fines for a failure to comply.

A command approach like S. 946 might have some appeal in its simplicity ${ }^{58}$ but this proposal simply does not address the root causes we discuss above. The market defect we focus on is not the transaction between the MVPD and the subscriber, but the fact that third parties, such as advertisers and programmers, are involved in the wealth-maximizing bundling decisions of the MVPD. An MVPD makes decisions about what channels to put on a tier not only by reference to what its subscribers prefer but also the revenue opportunities afforded to it by advertisers and programming vendors. ${ }^{59}$

\footnotetext{
53 See id. TII 101, 103.

54 See Brown \& Alexander, supra note 21, at 165.

55 Id.

56 Id.

57 Kid-Friendly TV Programming Act of 2005, S. 946, 109th Cong. (2005).

58 One might consider a requirement for a "family tier" of programming akin to a local zoning regulation that instructs bars in residential neighborhoods to turn their music down after a certain time, or a law that limits the sale of tobacco or adult magazines within a certain distance of a school.

59 See discussion supra Part III.B.
} 
The proposal also raises the question as to how to define what is a "child-friendly tier." S. 946 proposes to incorporate section 641(d) into the Communications Act of 1934, which defines "child-friendly tier" as "a group of channels that do not carry programming, advertisements, or public service announcements that would be considered inappropriate for children due to obscene, indecent, profane, sexual, or gratuitous and excessively violent content." 60 Because that definition is incorporated in to the Communications Act, the FCC would have the authority to interpret that definition and promulgate rules. ${ }^{61}$

This approach might, in fact, make the problem worse because it might strengthen the bargaining power that programming vendors have over MVPDs. Suppose that the only reasonably profitable means of offering a "child-friendly tier" is to include Nickelodeon and Noggin (both owned by Viacom) ${ }^{62}$ into that tier. Faced with a regulatory mandate to provide a tier of at least fifteen channels, the MVPD may need to provide even further concessions to Viacom (which also owns SpikeTV and MTV) ${ }^{63}$ with regard to tier placement of other, potentially-objectionable networks. Simply mandating a family tier of a particular size is like treating a symptom and not the disease; the welfare-reducing problem presented by forced bundling would remain for other consumers.

\section{Carrot and Stick: Senator McCain's "CHOICE Act"}

Senator McCain's CHOICE Act $^{64}$ takes a novel approach to the issue by conditioning pro-competitive and pro-entry reforms, such as national franchising $^{65}$ and a cut in the franchise fee, ${ }^{66}$ to the availability of à la carte programming. The CHOICE Act would offer a streamlined national cable franchise, ${ }^{67}$ and lower franchise fee obligations and other incentives to any "video service provider" that offers video programming to subscribers on an à la carte basis. ${ }^{68}$ The proposal would not prohibit the creation of bun-

\footnotetext{
$60 \quad S .946 \& 3$.

61 See 47 U.S.C. $\S \S 151,155$ (2002).

62 Viacom.com, Welcome to Viacom: Cable Television, http://www.viacom.com/cable.jhtml (last visited Nov. 12, 2006) (listing Nickelodeon and Noggin as a Viacom brand names).

${ }_{63}$ Id. (listing SpikeTV and MTV as a Viacom brand names).

64 Consumers Having Options in Cable Entertainment Act, S. 3457, 109th Cong. (2006).

65 S. $3457 \S 3$ (eliminating the requirement that video service providers obtain state or local video franchises).

${ }_{66}$ Id. at $\S 3$ (b)(1)(A)(ii) (limiting the fee that local governments can charge eligible video services).

67 See S. 3457 \& 3.

68 See id. The CHOICE Act also requires video service providers with an ownership interest in video programming networks not to prohibit other video providers from offering those affiliated channels on an a la carte basis. S. 3457 § 4 . According to the FCC, "five of
} 
dles of tiers, just that channels also be made available on an à la carte basis. In exchange, MVPDs are offered significant "carrots" in exchange for offering services on an à la carte basis.

Senator McCain's CHOICE Act also contains an important "stick" for programmers. Many broadcast licensees and broadcast networks also have an interest in cable programming networks. ${ }^{69}$ Current federal rules give these broadcasters the exclusive right to prohibit a cable operator from duplicating a network broadcast by transmitting a signal from another station in the broadcaster's community. ${ }^{70}$ In essence, the FCC's nonduplication rule gives Disney, which owns the ABC network in addition to ESPN, SoapNet and other cable channels, the ability to force a cable company to carry its cable networks on a particular tier, or the cable risks not being able to transmit $\mathrm{ABC}$ network programming. There is evidence that broadcasters have used this right in this manner. ${ }^{71}$ The CHOICE Act would terminate these non-duplication exclusivity rights for broadcasters unless the broadcaster permits video service providers to sell those channels on an à la carte basis. ${ }^{72}$

The carrot and stick approach of the CHOICE Act attempts to address the root causes we identify in a novel way. Importantly, unlike Senator Wyden's approach, the proposal does not simply look at the issue by reference to mandating that cable operators make family tiers available. ${ }^{73}$ Instead, Senator McCain's proposal recognizes that a market defect exists, that public policy (such as the non-duplication rule) might exacerbate that defect, and attempts to resolve it by creating countervailing incentives (such as national franchising). ${ }^{74}$ Every piece of incentive legislation,

the top seven cable companies (i.e., Comcast, Time Warner, Cox, Cablevision and Advance/Newhouse) have ownership interests in satellite-delivered national programming networks." In re Annual Assessment of the Status of Competition in the Market for the Delivery of Video Programming, Twelfth Annual Report, 21 F.C.C.R. 2503, II 159 (Feb. 10, 2006) [hereinafter Twelfth Annual Report].

69 See id. II 162.

$70 \quad$ See 47 U.S.C. $\$ 325$ (2000); 47 C.F.R. $\$ 76.64$ (2005).

7 See, e.g., In re A La Carte and Themed Tier Programming and Pricing Options for Programming Distribution on Cable Television and Direct Broadcast Satellite Systems, Discovery Communications, Inc., Ex Parte Notice, MB Docket No. 04-207 (Oct. 19, 2004) (accessible via FCC Electronic Comment Filing System) (arguing that retransmission consent policies result in forced carriage of cable programming networks affiliated with broadcast networks that displace services that subscribers would prefer); In re A La Carte and Themed Tier Programming and Pricing Options for Programming Distribution on Cable Television and Direct Broadcast Satellite Systems, Reply Comments of Turner Broadcasting System, Inc., MB Docket No. 04-207, at 17 (Aug. 13, 2004) (accessible via FCC Electronic Comment Filing System) (internal citations omitted).

${ }_{72}$ Consumers Having Options in Cable Entertainment Act, S. 3457, 109th Cong. § 4(a) (2006).

73 Compare S. 3457 with Kid Friendly TV Programming Act of 2005, S. 946, 109th Cong. (2005).

${ }^{74}$ See S. 3457 § $3(\mathrm{~A})(1)(\mathrm{a})$. 
though, has the drawback that the incentive offered might be too little to induce appropriate behavior, or that regulators might mishandle any such incentive and develop loopholes that will render them meaningless.

\section{Revenge of the "Clickers"}

One reason that this market defect is unresolved is because it may be difficult for individual consumers to express their strong preferences directly to advertisers and cable companies. Advertisers certainly do not wish to pay to advertise on networks that a consumer does not watch, but advertisers are not concerned with a parent's objections to particular programming as long as their kids watch it and buy the advertised products. ${ }^{75}$ Because information is imprecise, advertisers will, almost by definition, pay the cable operator or programming network some fee to deliver a programming network to a subscriber-even if that subscriber (or a parent of a viewer) finds the content on that network offensive. Also, even a small probability that a consumer's attention is captured by a channel that is generally objectionable renders some value to advertisements.

Placed in terms of the model, $S$ is made larger because of inefficiencies in the advertising market. As we describe above, if $S B$ (the revenue from a third-party advertiser that a cable firm receives by including Network B on its expanded basic tier) is large enough, the cable operator will force a bundle that includes Network B even if that consumer dislikes Network B $(V B<0)$. The consumer is less satisfied with the product he or she receives, but still subscribes as long as the value of the other programming on the expanded basic tier (VA) is large enough. ${ }^{76}$

The problem could be overcome if all of the consumers that find Network $\mathrm{B}$ objectionable could somehow organize and compensate the cable operator for blocking Network B. But organizing such a diffuse constituency is likely to be so costly that success will be unlikely. When transactions costs of organizing a constituency are high, some people feel that the government should rightfully act as a representative, thereby overcoming transaction costs. A mandated "family tier" or à la carte availability could be seen as a governmental effort to overcome these transactions costs, as their availability would give consumers the opportunity to opt-out of programming they deem objectionable. In doing so, that decision will communicate to cable operators, programmers, and advertisers that this portion of the market is not interested in viewing particular content. Reducing transactions costs in this manner is one reason why government exists.

75 Advertisers, of course, do not generally care if consumers like or dislike the channel; advertisers only care if the channel is watched. And stated simply, what parents would like their children to watch and what their children actually watch are two different things.

${ }_{76}$ See discussion supra Part III.C. 


\section{E. Anti-Tying Policies}

A more aggressive policy might simply forbid the "tying" of the distribution and carriage of one programming network to an agreement to carry another programming network on the same tier. While there is a vigorous debate over whether mandated family tiers and à la carte options are a sensible solution, a host of MVPDs and certain programming interests alike believe that the actions of large programming vendors results in expanded basic tiers that essentially encourage the proliferation of forced bundles of cable programming networks. This approach would be similar to the nonduplication ("stick") component of Senator McCain's CHOICE Act but on a larger scale, as it would cover all cable video programming networks, even those that are not affiliated with a broadcast network.

Unlike mandated à la carte, intervention in the wholesale market for MVPD programming may only need to be incremental to cause vast improvement. Government may not need to prohibit all forms of tyingpolicy may only need to prohibit tying that stipulates that the "tied" network be placed on the expanded basic tier in order for the MVPD to avail itself of a bundled price. Such a rule would permit MVPDs to create a variety of programming tiers that might result in placing, for example, $A B C$ Family on a "family tier" and ABC's SoapNet on an "adult tier," rather than have pricing essentially force the MVPD to place both on the "expanded basic" tier. This approach might also involve changes to the retransmission consent rules, ${ }^{77}$ which might facilitate and even reward programming vendors who engage in this practice.

\section{CONCLUSION}

Policymakers have expressed increasing concern that the "expanded basic" tiers of cable and satellite MVPDs often include programming that may be unsuitable to families with children. This discussion has prompted a number of proposals for solving this issue in the last year, several of which have attracted a particularly virulent firestorm of criticism from the cable industry.

Notably absent from this debate has been a practical, analytical analysis as to what market conditions would cause the proliferation of "expanded basic" cable programming tiers that effectively force consumers to allow into their households video content to which they object. In this article, we take a practical-and not ideological-approach to this issue. The proliferation of "expanded basic" tiers may be the result of a market defect caused by the operation of the upstream video programming and advertising markets. In short, the content, size, and price of expanded basic tiers is

\footnotetext{
77 See 47 U.S.C. $\$ 325$ (2000); 47 C.F.R. $\$ 76.64$ (2005).
} 
not solely the result of MVPDs providing to consumers programming that consumers demand. As a result, American families are often faced with the unpleasant reality that in order to obtain access to programming they may desire (like CNN or Nickelodeon), they may be required to subscribe to programming that they do not want their children to see (like MTV or SpikeTV).

This article explores the circumstances in which this form of market defect might impede that optimal mix or selection of programming choices to parents by multichannel video providers. "Family tier" or "à la carte" requirements might be a valid public policy response to a failure of the market to increase consumer welfare by providing adequate choices. Forced bundling might occur even in competitive markets, which means that policymakers cannot simply turn a blind eye to the issue by assuming that "bundling does not force consumers to pay for programming they do not want." 78

Finally, it is important to note that the potential market defect we identify here simply means that firms operating pursuant to market forces and profit motives may take actions that are not socially optimal. This article does not mean to imply that these firms are "up to no good." Nevertheless, it is the responsibility of policymakers to understand situations in which the market acting alone may not be adequate to promote the interests of consumers, and to intervene accordingly.

$782004 \grave{A}$ La Carte Report, supra note 24, at 23. 